\title{
Research on the Matching Relationship Between Teaching Team Maturity and Leadership in Colleges and Universities
}

\author{
Jidong Xue*, Fengkai Yue, Chunlan Yin, Shengnan Du \\ School of Business Management, Shanxi University of Finance and Economics, Taiyuan, China \\ *Corresponding author
}

Keywords: Teaching Team; Maturity; Leadership; Matching Relationship.

\begin{abstract}
In order to preferably lead the development of teaching team in colleges and universities, this paper makes a research on the matching of the maturity of the teaching team and the ability of the leader. In the forming period, team leaders should focus on developing insight; In the storming period, team leaders should focus on controlling communication; In the norming period, team leaders should focus on building trust; In the performing period, team leaders should focus on self-improvement. This paper can provide useful guidance for the norming period team leaders to promote the construction of teaching team in colleges and universities.
\end{abstract}

\section{Introduction}

It is an important way to strengthen the core competitiveness of local colleges and universities to establish a high-quality teaching team with high teaching level and strong cooperation ability which guided by advanced education concept and oriented by talent cultivation goal[1]. The role of team leadership cannot be ignored whether the teaching team can gradually mature. Team leader plays a significant role in the process of the teaching team gradually becoming mature. Teaching teams in different colleges and universities have different levels of development, even among teaching teams in the same one. For the construction of teaching team, if the team leader wants to give full play to his/her leadership role, he/she needs to carry out classified guidance according to the development forms of the team with different maturity, display his/her leadership in a targeted way. The leader of teaching teams can get twice the result with half the effort if he/she shows different levels of leadership according to the maturity of different teams. This paper systematically discusses the matching relationship between the leadership and the maturity of teaching teams in colleges and universities and it provides some reference and guidance for the connotative development of higher education.

The application of team maturity can well reflect the development level of teaching teams and provide a basis for defining the development stage of teaching teams. Team maturity refers to the degree to which team members agree on team goals and they can cooperate with each other. It can be divided into goal consensus maturity and relationship maturity. Goal consensus maturity refers to 
the degree to which team members reach consensus on team goals, while relationship maturity refers to the degree of interaction and collaboration between team members. According to the different levels of goal consensus maturity and relationship maturity, the maturity of teaching teams can be divided into four stages from low to high: forming period, storming period, norming period and performing period.

Combined with the characteristics of high quality and multiple abilities of teaching team leaders, this paper applies Bennis' four-dimension leadership model to divide the leadership of teaching team leaders in colleges and universities into insight, communication control, trust building and self-improvement[2]. The work contents of teaching team leaders can be divided into teaching, scientific research and management. Teaching is the fundamental work and the first priority of the teaching team leaders in colleges and universities. Scientific research work promotes the continuous improvement of teaching work, because in general only with a considerable level of scientific research, teaching work can have more depth and insight. As the person in charge of the teaching team, the management work is well coordinated that the teaching and scientific research can be carried out more smoothly and effectively[3]. Therefore, this paper masks the leadership of teaching team leaders in colleges and universities from teaching, scientific research and management.

According to the team life cycle theory, leadership contingency theory and the functions of the teaching team, as shown in table 1, the maturity of the teaching team in colleges and universities has a certain matching relationship with the leadership.

Table 1. The Matching Relationship Between Teaching Team Maturity and Leadership in Colleges and Universities

\begin{tabular}{|c|c|c|c|}
\hline $\begin{array}{c}\text { Work contents } \\
\text { of leaders } \\
\text { match between } \\
\text { maturity and leadership }\end{array}$ & Teaching & $\begin{array}{c}\text { Scientific } \\
\text { research }\end{array}$ & Management \\
\hline $\begin{array}{c}\text { Forming period } \\
\text { Insight ability }\end{array}$ & $\begin{array}{c}\text { Establish teaching } \\
\text { goals }\end{array}$ & $\begin{array}{c}\text { Identify academic } \\
\text { frontiers }\end{array}$ & Lead team building \\
\hline $\begin{array}{c}\text { Storming period } \\
\text { Communication control } \\
\text { ability }\end{array}$ & $\begin{array}{c}\text { Enhance interpersonal } \\
\text { relationship }\end{array}$ & $\begin{array}{c}\text { Improve research } \\
\text { mechanism }\end{array}$ & $\begin{array}{c}\text { Deal with team } \\
\text { conflict }\end{array}$ \\
\hline $\begin{array}{c}\text { Norming period } \\
\text { Trust building ability }\end{array}$ & Promote teaching \\
sharing & $\begin{array}{c}\text { Achieve scientific } \\
\text { research collaboration }\end{array}$ & $\begin{array}{c}\text { Engage in team } \\
\text { delegation }\end{array}$ \\
\hline $\begin{array}{c}\text { Performing period } \\
\text { Self-improvement }\end{array}$ & Strengthen & $\begin{array}{c}\text { Promote scientific } \\
\text { research innovation }\end{array}$ & charismatic leaders \\
\hline
\end{tabular}

\section{In the Forming Period of the Teaching Team, Team Leaders Focus on the Exercise of Insight Developing}

During the forming period, there is little understanding between team members and team leaders even among team members. Some team members may show instability and anxiety. This stage is characterized by the fact that team members have not formed consensus on the team's goals or established an interactive and collaborative atmosphere. In other words, the maturity of consensus on the team's goals and is low as the maturity of relationship. The main task of the forming period is 
to build a multi-faceted platform to invest the human resources and material resources for team construction so as to solve the problems of single internal structure and poor external resources and relations of the teaching team.

At this stage, the leaders of teaching teams in colleges and universities need not only to timely predict and perceive the changes in the requirements of the times, in the external environment and within the teams, scientific research results and management methods, but also to make corresponding responses in team management in a timely manner. That is to focus on the team leaders' insight.

The insight of teaching team leaders is embodied in the ability of establishing teaching goals, identifying academic frontiers and leading team development. Establishing teaching goals means that leaders need to pay attention to the external environment for the development of dynamic to work out the teaching goals of the team around the talent training goals and core education concepts. And they should attract the attention of the team members to the team works so that they can play their own advantage in the cultivation of talents, and at the same time, it is conducive to the growth of teachers and students[4]. Identifying academic frontiers means that leaders need to focus on the research work with an insight into the academic frontier to determine the research direction according to the goals of the teaching team and understand the research status. Leading team development means that leaders configure team members to establish the teaching team construction goal and task deadline. On this basis the leaders establish an effective organization form so as to make scientific task allocation and the reasonable benefit distribution mechanism thus the collaboration between the team members of interaction will be promoted.

\section{In the Storming Period of the Teaching Team, Team Leaders Focus on the Exercise of Communication Control}

Storming period is the second stage of teaching team development. During the Storming Period, although the team leader's insight and the cooperation among team members were recognized to some extent, with the gradual development of the teaching team, the team members' differences in research preferences, behavioral habits, knowledge background and other aspects led to interpersonal conflicts and differentiation among team members, dissatisfaction with their roles and other problems gradually emerged, resulting in mismatching between the teaching team and the surrounding environment. This stage is characterized by that although the team members have not yet formed a consensus on the team goals, the team members gradually show an interactive and cooperative atmosphere, that is, the goal maturity is low but the relationship maturity is high.

This stage is the turning point of the development of the teaching team. If this stage is well constructed, it will lay a good foundation for the subsequent development. The team leader should communicate with students, teachers and other external personnel to achieve a good control of the team operation to solve the above problems. That is to give play to the communication control of the team leader.

The communication control of teaching team leaders is embodied in the ability of enhancing interpersonal relationship, improving research mechanism and dealing with team conflicts. Enhancing interpersonal relationship means that leaders create a good interactive atmosphere and build a wide range of communication platform to organize regular team members communicate teaching experience. Therefore, the system of discussing courses with each other can give full play to the superiorities of old teacher's experience and the innovation of young teachers so that the in-depth understanding and communication between team members can be promoted to lay the solid foundation for the coordinated development among the team members. Improving research mechanism means that leaders should actively and deeply explore scientific problems, summarize 
the experience in dealing with teaching and share it with the teaching team. The wisdom of the team will be concentrated to promote the smooth completion of scientific research projects of the teaching team, so that the teaching team can form a virtuous circle of scientific research project application, completion and re-application[5]. Dealing with team conflict means that leaders should control team conflict well from the point of view of respecting team members and caring for the growth of team members, smooth and expand the channels of information communication, and give full play to the role of constructive conflict. Leaders should control the development direction of the teaching team and guide the members to work together to achieve the team goals as soon as possible.

\section{In the Norming Period of the Teaching Team, Team Leaders Focus on the Exercise of Building Trust}

With the improvement of the teaching team structure and the enhancement of the execution of work tasks, the difficulty of team management is gradually increasing, and regulations are required to restrict and regulate the behavior of members. Members can communicate openly and frankly with each other and cooperate with each other in a tacit way. At this time, the teaching team still has a certain dependence on the leader, but it can gradually transition to participatory leadership so the team has more autonomy. The characteristics of the teaching team in the norming period are: the team members gradually form consensus on the team goals, but the interactive and cooperative mechanism centering on the realization of the team goals is yet to be established, that is the goal maturity is high but the relationship maturity is low.

The development of teaching team is gradually on the right track, and communication between team members is no longer a problem. To further strengthen the construction of teaching team, trust plays a very important role in teamwork[6]. Only by sharing their achievements and resources with others, can the leaders of teaching teams give full play to the advantages of team cohesion to the greatest extent, so as to produce the collaborative effect of the team. That is to focus on the team leader's ability to build trust.

The ability to build trust of teaching team leaders of colleges and universities is embodied to promote teaching sharing, achieve scientific research collaboration, and engage in team delegation. Promoting teaching sharing means that leaders should pay attention to the realization of the sharing of teaching resources and organize team members to discuss the problems of teaching innovation about teaching design, course construction and classroom flip, etc. By working together to complete challenging tasks, the team transactive memory system can be established which make the information sharing and complementary between team members become practice. Thus, team members realize the faster development of teaching ability in the team. Achieving scientific research collaboration means that leaders should attach great importance to combining teaching activities with the completion of scientific research projects by team members, giving full play to the wisdom and innovative vitality of the team, and producing high-quality and efficient scientific research results so as to win the respect and recognition of team members ${ }^{[7]}$. Engaging in team delegation means that leaders should work hard on establishing an effective incentive mechanism, especially pay attention to the internal incentive means such as goal incentive, effect incentive and honor incentive so as to and express the leader's recognition of employees, stimulate the enthusiasm of work, and finally achieve the overall improvement of the teaching team.

\section{In the Performing Period of the Teaching Team, Team Leaders Focus on the Exercise of Self-Improvement}

In the performing period, the operation mode and rules and regulations of the teaching team are 
relatively sound and perfect. Meanwhile, it has formed a good interaction relationship with the external environment. The cohesion and morale of the team has been enhanced and the innovation of team has been improved. The team has achieved the best performance and established a good team atmosphere. The characteristics of a mature teaching team are as follows: team members have a high degree of identification with the team goals, and can exert the team synergy to achieve the team goals, that is, the goal maturity and relationship maturity are both high.

The role of the teaching team is more flexible and functional and the team energy is integrated. The work is completed smoothly and efficiently and there is no conflict and no supervision are needed. With the development of the times and the improvement of team construction, it is objectively required that the leaders of the teaching team should continuously improve their own abilities, improve their innovation ability and cultivate the indomitable spirit of seeking truth, so as to improve themselves to cope with the possible problems of the team in the future. That is to focus on the team leadership to improve the self-improvement.

The self-improvement of the teaching team is embodied in the abilities of strengthening professional quality, promoting scientific research innovation and developing charismatic leadership. Strengthening professional quality means that as a teacher, team leaders must do their best in the teaching field they are good at, constantly learn and absorb the latest knowledge, and enrich themselves. This kind of behavior will also become an example of the team and encourage team members to improve their own development. Promoting scientific research innovation means that in terms of scientific research, team leaders put forward new ideas, theories and methods with economic and social values to cultivate innovation consciousness, create innovation atmosphere and improve members' professional quality. Methods will be learned including reverse thinking, interdisciplinary and classified research, etc. Thus, their scientific research innovation ability can be enhanced. Developing charismatic leadership means that as the team manager, leaders must constantly improve the planning and integration ability and must have a thoughtful foresight which based on the reality and the future. The ability of decision making and execution should be improved to avoid problems that may be encountered by the teaching team in the future. The coordination ability has to be improved as well to be sensitive to the emotional changes of members to do preventive work in advance.

\section{Conclusion}

The construction of teaching team in colleges and universities is not only to meet the needs of subject construction and deepening teaching reform, but also to meet the needs of social development and talent cultivation. This paper adopts contingency perspective to analyze the matching relationship between the exercise of leadership ability of teaching teams and the accomplishment of different strategic goals and tasks by teaching teams in different development stages. This paper provides the direction for goals, content, and significance of the teaching team construction in colleges and universities, also provides useful guidance for the teaching teams with the development of a high teaching quality and the innovation ability of high level.

\section{Acknowledgement}

Fund project: National Educational Science Planning Project "Research on the Teaching ability of Young Teachers in Colleges from the Perspective of team Innovation" (DIA180377), "Shanxi Provincial Research on the Construction of Teaching team in Colleges and Universities from the Perspective of leadership role" (2015106), "Shanxi Research on the cultivation of innovative practical ability of Management College students" (2015103). 


\section{References}

[1] Zhiwen Cai. Research on big data Service platform for Teaching Innovation practice in Colleges and Universities[J]. Modern Educational Technology, 2017,27(04):117-123.

[2] Jidong Xue, Xasha Zhang, Yanhong Shi. Research on leadership competence of Teaching team in Colleges and Universities-based on Bennis leadership Theory [J]. Research on Higher Financial and Economic Education, 2017,20(01):17-21.

[3] Zhizhong Hong. The evolution and reconstruction of grass-roots teaching and research offices in colleges and universities [J]. University Educational Science, 2016(03):86-92.

[4] Baozhu Liu. The construction of high-water stroke teaching team promotes the improvement of undergraduate teaching quality [J]. Higher Education in China, 2007(05):29-31.

[5] Dan Xu. The construction of teaching team organization structure in vocational colleges: from the perspective of team life cycle theory $[\mathrm{J}]$. Research on the development of education, 2015,35(09):78-84.

[6] Weihua Ma, Dingding Xiao, Zhi Xu. The evolution path of core competence of academic team in colleges and universities based on life cycle theory $[\mathrm{J}]$. Exploration of Higher Education, 2012(04):91-96.

[7] Shuiyan Mei, Limin Li. Discussion on the Strategy of Teaching team Construction in Colleges and Universities [J]. Research On Higher Education Of Science And Technology, 2009,28(02):65-67.

[8] Xiaoyan Li, Daolin Xue. System and Mechanism: First-class Teaching and Construction of Scientific Research Team[J]. Higher Education in China., 2018(Z2):58-59.

[9] Fuli Yu, Yunzhi Ling. How to improve the teaching ability of college teachers from the practical level [J]. Higher Education in China, 2018(24):50-51.

[10] Jiandong Shao. Leadership of higher Vocational Teachers: connotation, value and Development path [J]. Jiangsu Higher Education, 2018(10):72-76. 